\title{
METODOLOGÍA DE LA CIENCIA EN GENERAL Y LA ECONOMÍA EN PARTICULAR
}

FRANCISCO CAPELLA*

\section{I VIDA, ACCIÓN, EVOLUCIÓN Y COGNICIÓN}

Los seres vivos son agentes autónomos autopoyéticos: mediante su actividad dinámica autocontrolada se mantienen, se regeneran a sí mismos y se reproducen utilizando materiales y energía de su entorno, el cual incluye materia inorgánica y otros seres vivos. La reproducción no es perfecta, de modo que los organismos de una misma especie no son idénticos, y sus diferencias pueden ser relevantes respecto a su capacidad de supervivencia y reproducción.

La vida evoluciona. La evolución es un proceso histórico, gradual y adaptativo de cambio entre generaciones de seres vivos que compiten por recursos escasos. Mediante el mecanismo de la selección natural las variantes más exitosas en un entorno tienden a desplazar a las relativamente menos aptas en las funciones básicas de supervivencia: aprovechar oportunidades (encontrar alimento, conseguir pareja reproductora) y evitar riesgos (depredadores, enfermedades, daños ambientales).

El comportamiento de un ser vivo está determinado por su estructura e interacciones. Los seres vivos son sistemas cibernéticos: controlan y coordinan su conducta mediante mecanismos de obtención y procesamiento de información acerca de sí mismos y de su entorno. Cada organismo vivo exitoso incorpora conocimiento e implica algún tipo de cognición. Los seres vivos más sofisticados disponen de subsistemas $u$ órganos especializados para estas tareas, los sistemas sensorial y nervioso.

\footnotetext{
* Instituto Juan de Mariana.
} 
La información incorporada en el aparato cognitivo de un ser vivo puede proceder de su programa genético innato y del aprendizaje durante su historia vital particular. Algunos seres vivos tienen programas de acción instintivos, rígidos, apenas modificables; otros tienen sistemas cognitivos más plásticos, modificables según el entorno y las vivencias individuales, de modo que es posible seleccionar (promocionar o reprimir) conductas entre un repertorio inicial; algunos seres vivos son capaces de innovar, de generar de forma creativa nuevas estructuras de acciones y probarlas en el mundo. Los seres vivos dotados de curiosidad se interesan por el aprendizaje, les motiva la adquisición de conocimiento, lo adquieren en el presente de modo que tal vez ya disponen de él cuando lo necesitan con urgencia en el futuro.

Con un sistema cognitivo potente que disponga de una buena representación del mundo es posible construir simulaciones mentales de la realidad, que permiten ensayar de forma virtual las posibles consecuencias de diversos cursos de acción alternativos (generar reacciones y predecir sus resultados antes de probarlas con riesgo real), y también construir planes de acción que conduzcan a objetivos dados (partir de un estado final deseado y computar cómo llegar a él desde la situación inicial actual). La cognición es especialmente adaptativa por la capacidad de predicción que permite prepararse para el futuro.

Si un animal tiene un repertorio extenso de conductas posibles, es necesario que disponga de un sistema selector de las mismas (no se puede intentar hacer todo a la vez), un aparato emocional o voluntad generadora de preferencias o prioridades que indique qué acciones son más adecuadas para la supervivencia, qué objetivos son más valiosos.

La acción de los seres vivos no es en general aleatoria (sin ningún tipo de control cognitivo y sin relación con la realidad), sino que consta de reacciones y en algunos casos de acciones intencionales. Las reacciones son procedimientos automáticos ejecutados ante estímulos específicos, externos o internos; los hábitos son reacciones provocadas por algún fenómeno periódico. La acción intencional es la realización de un plan consciente de utilización de medios y ejecución de acciones parciales más simples cuya combinación estructurada conduce a la obtención de un fin u objetivo 
deseado. La capacidad de acción intencional requiere un sistema cognitivo complejo que incorpore grandes cantidades de conocimiento general e información particular acerca del mundo. Los organismos capaces de acción intencional tienen una fuerte ventaja adaptativa: se adelantan en el tiempo, planifican, han preparado la acción y previsto de forma estratégica diferentes contingencias, no sólo improvisan sobre la marcha o reaccionan ante lo inmediato. Una acción intencional también puede considerarse como una reacción muy compleja, indirecta y diferida: las circunstancias ambientales e internas provocan la fijación de un objetivo que activa los mecanismos planificadores de la cognición.

Ciertos animales son capaces de imitar conductas ajenas, de modo que en lugar de probar y descubrir por sí mismos (con los riesgos asociados a proceder a ciegas en ámbitos novedosos) pueden copiar lo exitoso en un contexto social. El fenómeno de copia de conductas da origen a nuevos replicantes, los memes, que coevolucionan con los genes, de forma complementaria o competitiva.

II

PSICOLOGÍA EVOLUCIONISTA, MEMÉTICA, CONOCIMIENTO HUMANO Y CIENCIA

La psicología evolucionista estudia la mente humana como una herramienta adaptativa para la supervivencia en un entorno ancestral. El cerebro humano no es una hoja en blanco sobre la cual escribe la experiencia, sino que tiene mucha estructura especializada innata (información y algoritmos de procesamiento básicamente universales, comunes a la especie humana con algún grado de variabilidad) a partir de la cual seguir construyendo durante la vida de la persona.

La mente refleja el carácter hipersocial de la especie humana: importantes subsistemas de la sociedad de la mente (detectores de intencionalidad y procesadores del lenguaje) se dedican a gestionar la coordinación social, intentando averiguar las intenciones ajenas y las posibles reacciones ante los resultados de la conducta individual y permitiendo la comunicación lingüística. 
La cooperación social es posible gracias a sentimientos morales y sistemas de detección de tramposos. El ser humano es autoconsciente: la mente se representa a sí misma como parte de la realidad. La teoría innata de la mente humana, que todo individuo cognitivamente competente posee, permite la conducta intencional en el propio agente y la comprensión intuitiva de los comportamientos ajenos como acciones teleológicas.

La memética explica la cultura y las instituciones humanas: las conductas e ideas imitables se copian, especialmente mediante el lenguaje, lo cual permite su rápida proliferación. La memética estudia las ideas como reproductores evolutivos que tienen más o menos éxito según cómo sea su asimilación, retención, expresión y transmisión por sus portadores humanos.

El conocimiento humano es de muy diversos tipos: teórico o práctico, universal o particular, abstracto o concreto, sistemático o desordenado, explícito o implícito, declarativo o procedimental, conceptual o empírico, analítico o sintético, a priori o a posteriori. Estas distinciones no son categorías discretas perfectamente separadas sino que más bien reflejan los extremos de un espectro con variaciones graduales continuas.

Los seres humanos utilizan algunas ideas o memes para intentar representar conocimiento objetivo acerca del mundo. La ciencia es la sistematización del conocimiento humano sobre la realidad. La ciencia somete a los memes a selección mediante su correspondencia correcta con la realidad: las ideas científicas son comprobadas (verificadas o falsadas) en la medida de lo humanamente posible. La ciencia es el producto cultural más sofisticado de la evolución natural, una actividad cognitiva propia de los seres vivos inteligentes más desarrollados, los seres humanos con curiosidad intelectual y capacidades de observación y raciocinio.

III

\section{LA CIENCIA}

La ciencia estudia los fenómenos observables y las entidades que los producen, describiendo mediante teorías y leyes uniformes y constantes las regularidades en las relaciones entre objetos de 
la realidad. La ciencia busca principios fundamentales, causas últimas, verdades universales (entendidos estos conceptos de forma relativa, como más fundamental, más último, más universal, siempre dentro de ámbitos limitados).

El conocimiento científico es abstracto, formal, general, universal y comunicable de forma explícita. La ciencia trata de tipos, de generalizaciones. La ciencia estudia relaciones entre clases de sucesos particulares, expresadas con los conceptos de causa y efecto, y la estructura lógica de relación si antecedente, entonces consecuente. El conocimiento científico se representa simbólicamente mediante teorías, modelos conceptuales o sistemas de proposiciones en lenguaje natural o en los lenguajes formales de la lógica y las matemáticas. La teoría científica describe, explica, predice y es útil porque es aplicable, particularizable, concretable, interpretable, materializable para su uso en situaciones concretas.

La historia estudia sucesos particulares y necesita algún tipo de teoría previa para interpretarlos. La teoría científica sirve para interpretar la realidad histórica concreta; es una compilación, un resumen concentrado, condensado, comprimido, de conocimiento en principios fundamentales. El conocimiento científico también incluye datos concretos resultado de observaciones empíricas.

Una teoría es un modelo, un esquema conceptual, una representación abstracta, de alto nivel, simplificada, idealizada, de la composición, estructura y comportamiento de la cosa estudiada. Es un sistema formalizado, organizado, estructurado, articulado, unificado, integrado, de entidades y relaciones a distintos niveles: objetos, propiedades, atributos, valores, unidades, referencias, cantidades, cualidades, conceptos, clases, tipos, procedimientos, fenómenos, instancias, proposiciones, reglas, leyes, circunstancias, axiomas, teoremas, hipótesis, premisas, conclusiones, datos, información, conocimiento, sabiduría. Toda teoría es una síntesis y una simplificación, una aproximación válida dentro de un dominio o rango de aplicación.

El conocimiento científico (y en general todo el conocimiento y el pensamiento adecuado) tiene una serie de características ideales, unos criterios abstractos objetivos y universales de perfección independientes del dominio o asunto. Una teoría 
científica satisfactoria debe, en la medida de lo posible, dependiendo de la complejidad de lo estudiado y de las capacidades cognitivas de los investigadores, describir, explicar y predecir, de forma correcta, completa, consistente, eficiente, precisa, clara $\mathrm{y}$ aplicable.

Las ciencias naturales de lo inorgánico utilizan solamente la noción de causalidad. Las ciencias biológicas añaden la noción de funcionalidad: algo existe y es como es por cómo funciona de forma adaptativa para contribuir a la supervivencia del organismo. Las ciencias humanas añaden un tipo especial de funcionalidad, la intencionalidad como tipo de conducta (propia no solamente de seres humanos pero especialmente relevante en su naturaleza).

IV

\section{EL MÉTODO CIENTÍFICO}

Una proposición es científica si se refiere a algo real y si es posible de algún modo decidir si es correcta (verificación) o incorrecta (falsación). El método científico es un procedimiento sistemático, ordenado, planificado, organizado, para obtener conocimiento científico. La ciencia utiliza teorías y observaciones como herramientas y productos. La teoría explica las leyes observables concretas, las cuales son deducibles como casos particulares. Dada la multiplicidad de ámbitos de la realidad, las distintas ciencias se especializan en los diversos aspectos de lo existente. Cada ciencia debe utilizar medios adecuados a su objeto de estudio y a las capacidades y limitaciones de los seres humanos. La filosofía de la ciencia relaciona los distintos ámbitos de estudio y explica lo común y lo diferente a las diversas ciencias.

Una teoría científica está constituida por proposiciones con distinto grado de universalidad estructuradas mediante diversas relaciones lógicas de implicación. Algunas proposiciones implican a otras pero no son implicadas por ninguna otra (axiomas). Otras proposiciones sólo son implicadas por otras, y algunas implican y son implicadas (teoremas finales e intermedios).

La asimetría de la relación de implicación entre antecedente y consecuente tiene fuertes consecuencias para el método científico. 
La inferencia basada en la implicación lógica puede realizarse mediante modus ponens (de la verdad del antecedente se infiere la verdad del consecuente) o mediante modus tollens (de la falsedad del consecuente se infiere la falsedad del antecedente). Lo general (la teoría abstracta más genérica) implica lo particular (el caso más concreto, en el extremo el dato empírico individual, recogido por la ley general). Si lo que se conoce con seguridad es la ley general, todos los casos abarcados por la misma se conocen también con seguridad (método apodíctico deductivo). Si lo que se conoce con seguridad es el caso particular, no es posible generalizar con absoluta certeza (problema de la inducción): el caso particular elimina todas aquellas leyes generales que son incompatibles con él (las que implican que ese dato no se produzca), pero puede haber múltiples leyes generales compatibles entre las cuales no es posible decidir (método hipotético deductivo).

El método hipotético deductivo no garantiza el acierto pero evita el error mediante la falsación experimental (a posteriori). Las teorías son modelos hipotéticos no comprobables directamente, los puntos de partida son conjeturas no necesariamente verdaderas; sólo son comprobables las predicciones concretas observables implicadas por la teoría, y estas sólo pueden falsificar o refutar una teoría (si no se cumplen), pero no verificarla; si la teoría es correcta, las consecuencias se cumplen; si las consecuencias no se cumplen, la teoría no es correcta; si las consecuencias se cumplen, no se puede en general establecer que la teoría sea correcta, ya que podría haber otras teorías diferentes con las mismas consecuencias observables. El método hipotético deductivo acepta la lógica deductiva como apodícticamente correcta y considera verdaderos los resultados de las observaciones experimentales, pero siempre son posibles errores en la observación y en los razonamientos.

El método hipotético deductivo es de prueba y error: generar conjeturas y probar si sobreviven los ensayos de la experimentación. El científico intenta explicar un hecho o fenómeno observado (alguna regularidad, alguna pauta recurrente) proponiendo como hipótesis un modelo teórico que prediga dicho fenómeno y otros fenómenos potencialmente comprobables que permitan la refutación o la aceptación tentativa de la teoría. El investigador 
genera de forma creativa e imaginativa unas hipótesis o conjeturas para intentar explicar la realidad, y a continuación las critica y comprueba sistemáticamente para su aceptación o rechazo. Las hipótesis son explicaciones provisionales que por lo general no pueden ser verificadas directamente, pero pueden ser falsificadas, refutadas mediante observaciones o experimentos especialmente diseñados, si los hechos concretos predichos por la teoría, sus consecuencias contrastables, no concuerdan con los datos empíricos.

La ciencia busca explicaciones conceptualmente aumentativas que solucionen problemas planteados por un conjunto de conocimientos concretos (hechos, observaciones, resultados experimentales) cognitivamente independientes del modelo explicativo: varias hipótesis pueden ser compatibles con las observaciones, la explicación no es deducible lógicamente de las observaciones ya conocidas. Si las comprobaciones experimentales son numerosas y adecuadas, es menos probable que las hipótesis sean falsas (se reduce el espacio de búsqueda). Si se consigue demostrar que todas las demás alternativas son inválidas, la que sobrevive, la única posible, es la correcta: la posibilidad de hacerlo depende de la cantidad y la tipología de las teorías posibles y los datos obtenibles; no es siempre cierto que los datos sean finitos y las hipótesis infinitas (a menudo están fuertemente restringidas por criterios formales).

Las teorías científicas son memes en competencia, unidades intelectuales con personas como portadores, y pueden variar, difundirse, retenerse o extinguirse. El avance de las ciencias naturales es similar al progreso en la evolución natural. La evolución natural tiende a producir mejoras en la adaptación: el conocimiento va acumulándose y perfeccionándose. Los avances se deben a la selección natural que opera sobre las distintas variantes que se propagan con distinto éxito. Ninguna variación es un éxito o mejora a priori, su adecuación se muestra por su supervivencia en un entorno selectivo. La sucesión de teorías en las ciencias naturales es un proceso similar de eliminación empírica selectiva y adaptación incremental entre la teoría y los hechos de la realidad. Las teorías científicas se seleccionan mediante la confrontación con la observación. La experimentación no pretende justificar teorías (su aceptación es tentativa), sino falsificar teorías 
erróneas y seleccionar de forma tentativa y provisional la más idónea, la más competitiva, la más viable, la que es comprobable de forma más rigurosa.

El carácter provisional de las teorías científicas no significa que estas sean de baja calidad y que pronto serán rechazadas y abandonadas: a menudo una teoría considerada correcta es mucho mejor que otras posibles alternativas y ha sobrevivido duros ataques y críticas; una teoría mejor probablemente no la sustituirá sino que solamente la ampliará o perfeccionará de forma marginal, y las diferencias pueden ser tan pequeñas como para ser prácticamente irrelevantes en muchos ámbitos.

El método apodíctico deductivo mantiene la verdad mediante la verificación demostrativa. El conocimiento se comprueba en los axiomas apodícticos (no hipotéticos) evidentes, a partir de los cuales se infieren mediante deducción lógica diversos teoremas.

\section{$\mathrm{V}$ \\ ECONOMÍA: PRAXEOLOGÍA Y/O POSITIVISMO}

El orden de la realidad (existencia de regularidades y conexiones entre lo que es) no debe confundirse con la orden como mandato (lo que debe ser). El lenguaje humano es fundamentalmente manipulador y coordinador, no surge para describir el mundo sino para influir e interaccionar con los demás, y es natural que en etapas precientíficas muchos pensadores insistieran en moralizar más que en explicar: el mundo es como es por voluntad de la divinidad o del poderoso legislador expresada en forma de mandatos, deberes y prohibiciones. Pero el lenguaje humano también sirve para describir y conocer la realidad, y las ciencias positivas se limitan a describir y explicar la realidad sin juicios de valor (positivismo vs. normativismo).

El positivismo se refiere también la exigencia de comprobación empírica de las teorías científicas (método hipotético deductivo) mediante fenómenos observables (si es posible con cuantificación y medición y con modelos formalizados mediante lenguaje matemático) de modo que el discurso verbal no se quede en tautologías posiblemente poco informativas o disquisiciones metafísicas 
imprecisas o desconectadas de la realidad. La afirmación positivista de que el conocimiento sólo puede validarse mediante la experiencia empírica concreta es problemática. El propio postulado positivista pretende ser conocimiento pero no tiene sentido validarlo empíricamente (puede considerarse como metaconocimiento con criterios de adecuación diferentes).

La naturaleza (inorgánica y orgánica) es simple comparada con la complejidad de los seres humanos y la sociedad. En las ciencias naturales, inorgánicas y orgánicas, el método científico es hipotético deductivo y son posibles y útiles la cuantificación y la medición. En las ciencias humanas y sociales el método científico puede ser también apriorístico deductivo (praxeología a partir del axioma de la acción humana intencional) y las cuantificaciones y las mediciones son difíciles y problemáticas. Existe un interesante debate metodológico entre praxeólogos (escuela austriaca) y positivistas (neoclásicos).

\section{VI \\ LA PRAXEOLOGÍA}

La praxeología es la teoría general (el análisis formal) de la acción humana intencional. La praxeología está fundamentada en principios y características esenciales, universales y básicamente inmutables de la naturaleza del ser humano. La praxeología no analiza el contenido de la acción humana (los fines y medios concretos) sino solamente su forma lógica. Las leyes económicas son universalmente válidas, se cumplen siempre, no dependen de la naturaleza de los fines concretos de cada acción (egoístas o altruistas, materiales o espirituales, refinados o vulgares). La economía es la parte de la praxeología que incluye el estudio de la acción de los individuos aislados y la cataláctica (el análisis de los intercambios voluntarios entre personas en una sociedad extensa).

La historia estudia el contenido concreto de las acciones humanas a lo largo del tiempo, los acontecimientos humanos sucedidos en el pasado, interpretándolos mediante la comprensión y la aplicación de teorías. La interpretación histórica requiere 
teorías previas y juicios de relevancia. El historicismo es la falacia consistente en creer que no existen leyes económicas, que no es posible una teoría formal de validez universal, sino sólo hechos históricos.

La psicología estudia los contenidos de las decisiones humanas, cómo y por qué las personas eligen determinados objetivos o tienen determinadas conductas. Las ciencias naturales, la tecnología y la ingeniería estudian cómo utilizar medios para alcanzar fines.

La praxeología utiliza lógica verbal, inferencia deductiva y relaciones de causalidad (si se cumple un hecho y ese hecho es antecedente o causa de otro consecuente o efecto, entonces este último hecho también se cumple). La lógica puramente formal o simbólica (principios universales del pensamiento humano) es el fundamento abstracto de la praxeología, al cual se añade el axioma de la acción humana y todas sus circunstancias empíricas particulares. La lógica verbal resultante es una representación de conocimiento significativa, útil, clara y eficiente.

La metodología de la praxeología es diferente de la metodología de las ciencias naturales. La praxeología es una ciencia apriorístico deductiva: partiendo de axiomas conocidos, verdaderos, evidentes, irrefutables, apodícticos, se deducen teoremas o leyes. Las proposiciones praxeológicas y económicas son sintéticas a priori, no meras hipótesis: tienen contenido informativo relevante acerca de la realidad y no es necesario comprobarlas empíricamente. La praxeología es diferente de las ciencias físicas o naturales (hipotético deductivas), en las cuales se parte de premisas hipotéticas de las cuales se deducen consecuencias observables que permiten aceptar tentativamente las hipótesis o refutarlas. El axioma de la acción humana (el ser humano actúa) es irrefutable, no puede discutirse sin contradecirse: cualquier intento de demostrar su falsedad es una acción humana intencional que lo verifica. La teoría praxeológica no surge de la observación empírica, sino de la reflexión racional del ser humano pensante y actor. Las leyes praxeológicas señalan relaciones cualitativas entre diferentes entidades: son leyes de tendencia ceteris paribus, que indican cómo depende una entidad de otra si todos los demás factores relevantes permanecen constantes; o de forma 
equivalente son enunciados contrafácticos, que señalan diferencias cualitativas entre situaciones futuras dependiendo de que se haga o no algo.

Desde la perspectiva de la praxeología la economía es la ciencia que estudia los procesos sociales dinámicos de interacción y coordinación espontánea resultado de la acción humana individual creativa y empresarial en condiciones de escasez e incertidumbre. La economía no es solamente una teoría de la decisión o una mera técnica optimizadora o maximizadora de una función objetiva con unas restricciones dadas en condiciones estáticas de equilibrio, con toda la información sobre fines y medios conocida y constante.

La economía no analiza el contenido concreto de los fines de la acción humana, ni emite juicios de valor. De forma utilitarista la economía estudia si los medios son adecuados para los fines. Fines y medios son analizados formalmente como resultado de un flujo continuo de creación, transmisión y procesamiento de información que surge del proceso empresarial de interacciones humanas. Los individuos generan constantemente nueva información al buscar los fines y los medios que consideran relevantes en cada circunstancia particular. El conocimiento respecto a los fines y medios (que son muchos, diversos y cambiantes) no está dado ni es constante, se encuentra disperso en la mente de muchos seres humanos que continuamente lo crean y lo transmiten. Es posible que los actores económicos se equivoquen, se arrepientan, o no aprovechen todas las oportunidades de ganancia.

La economía es una ciencia humanista y se basa en el individualismo y el subjetivismo metodológico. La unidad fundamental de análisis económico es el ser humano protagonista, el individuo que valora, piensa, elige, decide y actúa según sus preferencias subjetivas y capacidades particulares limitadas. Las personas son por un lado emprendedores creativos y por otro imitadores, responden a incentivos y desincentivos y pueden cambiar de opinión. El ser humano es social, pero son los individuos los que actúan. Estudiar la acción humana aislada antes de analizar las interacciones sociales es un método adecuado de investigación y enseñanza, procediendo de lo simple a lo complejo. 
Es muy problemático concebir la economía de forma estrecha a imagen y semejanza de las ciencias naturales (cientismo, positivismo ingenuo), especialmente de la física más anticuada. Las ciencias humanas son diferentes de las ciencias naturales y mucho más complejas. La acción humana se explica con términos como intencionalidad (tendencia a la realización de valores), teleología, finalidad, volición, racionalidad. La economía no trata exclusivamente sobre cosas materiales de la naturaleza, sino sobre los seres humanos, su mente, sus ideas (correctas o incorrectas), sus apreciaciones y sus acciones (adecuadas o inadecuadas) respecto a la realidad. Los conceptos económicos fundamentales no son simples hechos objetivos directamente observables del mundo exterior (los bienes económicos), sino que se refieren a percepciones, pensamientos y valoraciones de los seres humanos (los agentes o actores económicos). Las características de las entidades reales son objetivas, pero las valoraciones de las personas son subjetivas: dependen de forma esencial del sujeto que valora (único e irrepetible), y no sólo del objeto valorado.

La praxeología es una ciencia formal en el sentido de que no estudia las valoraciones sustantivas específicas que motivan la acción humana. Pero la praxeología está íntimamente relacionada con las ciencias normativas (ética, derecho), ya que toda acción se desarrolla en un marco institucional restrictivo (implícito o explícito), y es posible realizar análisis de los efectos económicos de diferentes sistemas legales (economía del derecho, institucionalismo).

La economía no es una ingeniería social, y el conocimiento económico muestra que no es posible coordinar la sociedad de forma intervencionista y centralizada mediante mandatos coactivos. El racionalismo constructivista es en realidad un romanticismo irracional. La economía sirve de apoyo a la ciencia ética para descubrir los principios sociales de comportamiento adecuado, las normas o formas pautadas de comportamiento (instituciones) que son conformes al proceso espontáneo de coordinación humana movido por la fuerza de la función empresarial. La propiedad privada es el principio ético esencial que permite el uso eficiente de los recursos; las intervenciones estatales en el mercado libre son siempre destructivas. 


\section{VII \\ PRAXEOLOGÍA Y POSITIVISMO: PROBLEMAS, CONFLICTO Y COMPLEMENTARIEDAD}

Ambas aproximaciones a la ciencia económica (praxeología de los austriacos y positivismo de los neoclásicos y otras corrientes) tienen sus ventajas y potencialidades y sus límites e inconvenientes. Los defensores de cada escuela a veces exageran de modo algo sectario las virtudes propias y los defectos ajenos, y las críticas pueden basarse en la distorsión o la incomprensión. Tal vez sea posible algún grado de conciliación y complementariedad, ya que no son necesariamente incompatibles si ambas se interpretan con sensatez. Los conflictos fundamentales se refieren a los problemas de cuantificación, medición, matematización, predicción, experimentación, constatación empírica, subjetivismo, constancia, variabilidad, equilibrio.

Los austriacos niegan la posibilidad de cuantificación, medición, matematización, predicción, experimentación y constatación empírica, e insisten en que en economía no hay constantes ni equilibrios, sino sobre todo variación dinámica y subjetiva. Los neoclásicos intentan cuantificar, medir, matematizar, predecir, experimentar, constatar empíricamente, y a menudo sus modelos son simplificaciones donde se asume uniformidad y equilibrio.

La praxeología, al no cuantificar, pierde el sentido de la intensidad de las causas y los efectos. Indica tendencias cualitativas (crecimiento o decrecimiento de una entidad en función de otra), pero no fuerza de esas tendencias (que pueden ser considerables pero tal vez sean ridículamente pequeñas, despreciables). Por ejemplo la imposibilidad del socialismo debida al problema del cálculo económico es cuestión de escala y complejidad: cantidad y diversidad de personas, medios y fines de una sociedad (hay una cuantificación gradual implícita); además del problema del conocimiento existe el problema de los incentivos, y la praxeología no puede asegurar apodícticamente cuál es más importante. La ausencia de relaciones es aleatoriedad, que no es lo mismo que complejidad. Cuantificar entidades requiere resolver el problema (en ocasiones nada fácil y de solución parcialmente arbitrario) de qué es una entidad y cómo contarlas. Ni la cuantomanía 
(insistir en medirlo todo) ni la cuantofobia (no aceptar ninguna medición como científica) parecen adecuadas en economía.

Las valoraciones humanas son íntimas y subjetivas y no está disponible un instrumental o estándar objetivo de medición y comparación de preferencias o utilidades, pero al tratar las escalas de preferencia solamente como números ordinales sin métrica se pierde la información (quizás muy relevante) de la intensidad (absoluta o relativa) de dichas preferencias (que obviamente existen). Las preferencias humanas son resultado de la compleja actividad de procesamiento físico de información por el cerebro, y tal vez la psicología y las neurociencias avancen hasta conocer con más detalle su naturaleza. Es epistemológicamente muy arriesgado (y quizás arrogante) asegurar con rotundidad que es imposible cuantificar las valoraciones humanas (muy difícil no es equivalente a imposible, y demostrar imposibilidad suele ser muy difícil); tal vez lo sea ahora pero no en el futuro, y quizás se consiga mediante modelos sofisticados, dinámicos y estructurados de sociedad de la mente (donde una preferencia no estará representada por un único número sino por una compleja estructura de datos que refleje los múltiples agentes especializados y sus interacciones).

Los praxeólogos insisten en considerar solamente las preferencias demostradas en la acción. Es cierto que la acción (observable) demuestra preferencia (mental), que la acción intencional es impulsada y dirigida mediante la voluntad. Pero algunas preferencias no se traducen en acción ya que la capacidad humana es limitada; hay preferencias respecto a sucesos que no son resultado de la acción del propio agente; es posible estudiar preferencias hipotéticas respecto a hechos no realizados (curvas de demanda y oferta). Las preferencias no observadas también existen (introspección, vida subjetiva íntima), a veces no impulsan la acción porque no alcanzan la intensidad suficiente o porque se anulan unas a otras, interfieren de forma destructiva (miedos, bloqueos), pero eso no es lo mismo que si no existieran. La indiferencia no impulsa la acción, pero las curvas de indiferencia pueden ser una herramienta útil como aproximación (teniendo en cuenta sus limitaciones), describiendo un ámbito límite donde la acción no sucede en los puntos de indiferencia sino a sus lados. 
Los praxeólogos insisten en que la economía es una ciencia lógica y formal de la acción humana intencional, independiente de los contenidos concretos de los fines y las valoraciones subjetivas (que serían estudiados por la psicología o la timología), pero esto es una definición arbitraria no aceptable para otros economistas a quienes también interesa (y por eso lo incluyen) la formación de preferencias (que son explicables como adaptaciones evolutivas conectadas con la realidad del entorno). Algunos praxeólogos parecen empeñados en encerrarse en un ámbito con límites rígidos y no buscar conexiones con el resto del mundo científico: esto podría explicar (al menos en parte) su carácter minoritario y marginal, y también su lamentable rechazo de hechos científicos constatados en otros ámbitos (como la evolución biológica, en ocasiones sustituida por el creacionismo anticientífico y la superstición religiosa).

Los praxeólogos se interesan mucho por la metodología (y los positivistas quizás demasiado poco), pero a veces confunden problemas de ontología (lo que las cosas son) con problemas de epistemología (lo que puede conocerse de ellas y cómo): que algo no pueda conocerse (o sea muy difícil hacerlo) no significa que no exista o que no sea importante. No se trata de que no existan relaciones funcionales en economía, sino de que son tan complejas que es muy difícil conocerlas con precisión (la no existencia de relaciones implicaría aleatoriedad, que no es lo mismo que complejidad). Una función significa que existe una relación (ontología), otra cosa es que sea tan compleja que no pueda conocerse (epistemología) con precisión (pero quizás sí algunas características cualitativas de esa función, como la variación monótona).

Los praxeólogos insisten en la fundamentación de la economía mediante razonamientos lógicos, pero en ocasiones cometen errores lógicos graves (que demuestran que su dominio de la lógica y la metalógica no es profundo) o no consiguen ponerse de acuerdo sobre asuntos muy importantes (dinero, banca, crédito, propiedad intelectual), lo cual resulta raro si se insiste en que la lógica es una herramienta perfecta común a todos los seres humanos. Se supone que el lenguaje natural humano es la herramienta adecuada para la ciencia económica, pero a 
menudo no se reconocen sus limitaciones: los significados de los términos son problemáticos, de límites casi siempre difusos. El racionalismo extremo ignora que las categorizaciones absolutas y sin grados de la lógica clásica a menudo no son realistas ni prácticas, y suele despreciar problemas importantes de hermenéutica.

Los praxeólogos creen que lo empírico, lo estadístico, no añade nada relevante, y lo afirman con excesiva seguridad y rotundidad. La experimentación y la constatación empírica son problemáticas y muy difíciles en economía, y en ocasiones son innecesarias. La historia concreta es producto del funcionamiento conjunto de múltiples factores o influencias variables, en general no controlables, no repetibles y no separables. En la realidad nunca se producen las condiciones de ceteris paribus que permitirían contrastar (confirmar o refutar) empíricamente las leyes económicas. Pero la economía no es la única ciencia que se enfrenta a este problema, que se produce en todos los sistemas complejos (la medicina adolece de límites semejantes y tiende a funcionar al menos de forma marginal). Tal vez la variabilidad de los fenómenos no sea tan intensa, y quizás de la multiplicidad de factores algunos sean claramente más determinantes que otros y muchos pueden resultar despreciables. Los análisis estadísticos pueden indicar correlaciones entre diferentes variables que ofrezcan pistas para buscar relaciones causales entre las mismas.

Resulta absurdo intentar demostrar empíricamente leyes praxeológicas que se saben correctas mediante el análisis lógico. Pero quizás las mediciones econométricas estadísticas del comportamiento económico no sean meros registros históricos sin valor teórico (datos concretos contingentes sin validez universal) y sirvan parcialmente para precisar las leyes a priori y para descubrir nuevas relaciones no apodícticas (pueden existir relaciones que la mente humana no conoce a priori). De todos modos conviene ser muy cuidadoso con la observación y la experimentación en economía, ya que la medición social es muy compleja (en su realización y en su interpretación, que puede sufrir múltiples prejuicios ideológicos y ser manipulados) y los errores pueden resultar enormemente dañinos para los seres humanos (como intentar implementar el socialismo). 
La utilidad del conocimiento procede de su capacidad de predicción para guiar la acción. Pero en economía la predicción específica, concreta y detallada (cuantificada y temporalmente precisa) es muy difícil (prácticamente imposible), debido al carácter complejísimo y variable de los procesos sociales. Ningún observador puede obtener ni procesar la enorme cantidad de información práctica, subjetiva, dispersa, implícita, tácita, concreta y variable que constantemente están creando y descubriendo de manera descentralizada los actores económicos. El ser humano no puede predecir su conocimiento futuro. La praxeología sólo proporciona predicciones seguras de carácter general, cualitativas, de tendencia. La forma universal de la acción humana intencional es perfectamente predecible, pero no así sus contenidos.

Los praxeólogos asignan la función de predicción tentativa del futuro a los empresarios, pero existe un continuo entre la teoría abstracta más pura y los datos históricos particualres, y en economía quizás existan regularidades materiales y no solamente formales. Algunos economistas afirman poder realizar predicciones concretas, pero no lo demuestran en la realidad (enriqueciéndose mediante su acierto empresarial); quienes crean que sus predicciones no son fiables pueden apostar contra ellos. Una teoría puede parecer intuitivamente poco realista, pero si acierta (o es por lo menos mejor que las alternativas) de forma consistente en las predicciones indicará que las apariencias engañan y que la simplificación es informativa acerca de la importancia relativa de los factores considerados y los ignorados.

Para los praxeólogos el formalismo de la ciencia económica es la lógica verbal, abstracta y formal, que permite el análisis de procesos dinámicos; como la economía no es una ciencia cuantitativa, las matemáticas son inútiles e incluso engañosas (los deseos, las utilidades, las preferencias temporales de los individuos, son subjetivos y no pueden medirse, ni compararse entre distintos sujetos, ni sumarse).

El lenguaje humano no puede hacerse infinitamente preciso, y las matemáticas utilizadas con sensatez pueden ayudar a formalizar las teorías económicas. Pero la economía matemática frecuentemente produce análisis de equilibrio, estacionarios, estáticos, donde apenas se aprecia la acción humana y los resultados 
finales predominan sobre los procesos que llevan a ellos. La matemática es una herramienta potente y sofisticada, pero su uso inadecuado puede ser desastroso.

Los modelos matemáticos y las hipótesis de trabajo de algunas escuelas macroeconómicas representan situaciones arbitrarias, artificiales, distorsionadas y excesivamente simplificadas, que tienen poco o nada que ver con la realidad. Estos modelos son utilizados por presuntos expertos económicos para realizar recomendaciones políticas e intervenir coactivamente en la sociedad: pero ignoran los auténticos problemas económicos, no tienen en cuenta la creatividad, la empresarialidad (la fuerza básica del desarrollo económico), la causalidad, las limitaciones cognitivas, la incertidumbre, la obtención, procesamiento y utilización de información, la subjetividad y variabilidad de las valoraciones, el carácter enormememte complejo, dinámico y evolutivo de la sociedad y el mercado, la imposibilidad de medir y computar utilidades. Pero no es justo criticar toda la economía matemática simplemente porque algunos modelos sean excesivamente simplistas y claramente irreales. Las ecuaciones diferenciales y sus soluciones funcionales pueden hacerse muy complejas y cada vez más realistas: no es prudente asegurar con rotundidad que ninguna sirve y que nunca servirán para nada.

Los parámetros estadísticos o agregados macroeconómicos (clases globales que presuntamente resumen entidades heterogéneas, como el nivel general de precios o el producto interior de una nación) de las ciencias humanas en ocasiones están mal definidos, ocultan los fenómenos microeconómicos, enmascaran la complejidad subyacente, las variaciones locales relativas, se abusa de ellos en vez de utilizar unidades incrementales o marginales, y pueden ser menos interesantes y relevantes que los comportamientos individuales subjetivos. La utilización de la estadística en la sociedad, considerada como un agregado de elementos humanos, puede servir para realizar estudios sociológicos y de mercado, pero también puede resultar absurda y a menudo se utiliza para el control violento por parte del estado.

Los praxeólogos critican el cálculo diferencial por exigir una continuidad irreal y poco aplicable a la realidad humana. Olvidan que la problemática de lo discreto frente a lo continuo existe en 
todos los ámbitos de la realidad, y que también existen matemáticas avanzadas de lo discreto, pero a menudo se recurre a lo continuo porque puede ser una buena aproximación y su manipulación es mucho más sencilla. No se trata de que las diferencias infinitesimales causen la acción (los cambios muy pequeños son imperceptibles), sino que el cálculo infinitesimal puede ser una herramienta útil. Las relaciones funcionales de las ecuaciones matemáticas no necesariamente ocultan las relaciones de causalidad (es una información que puede ser considerada aparte). La utilización de métodos estocásticos en ocasiones puede servir para simular la complejidad de algunos fenómenos económicos.

Los praxeólogos a menudo critican el positivismo de las ciencias naturales fijándose exclusivamente en la física clásica, la cual estudia sistemas mucho más simples que los humanos. La física moderna ha avanzado mucho desde entonces y ya no estudia solamente sistemas simples en equilibrio, sino que trata la complejidad y los procesos dinámicos altamente no lineales. Además existe un ámbito intermedio entre la física y la economía que es la biología, donde ya hay acción (aunque en general no intencional), escasez, beneficios, pérdidas, competencia, cooperación, conocimiento imperfecto... El modelo adecuado de la ciencia económica no es la física de sistemas mecánicos simples sino la biología evolutiva (sistemas complejos autopoyéticos, adaptativos, cibernéticos, cognitivos), de la cual lo humano es un caso particular con características únicas.

Los praxeólogos insisten en que los seres humanos no son simples ni homogéneos ni constantes, y sus interacciones son muy variadas y complejas, de modo que en la sociedad humana apenas hay equilibrio, estabilidad o uniformidad. Que la realidad humana social sea dinámica, cambiante y diversa no quiere decir que tenga que cambiar sistemáticamente de modo que nada sea mínimamente invariante. Importa la magnitud del cambio y la diferencia, en ocasiones la constancia y la igualdad son buenas aproximaciones (y en otros casos muy malas) o al menos primeros intentos para ulteriores modelos más sofisticados.

Insistir en la diversidad puede llevar a olvidar la naturaleza común, que no está solo en lo formal, como muestra la psicología evolucionista. Los seres humanos son únicos e irrepetibles, 
pero muchas diferencias pueden ser irrelevantes. Los seres humanos pueden ser creativos y emprendedores, pero quizás la mayor parte del tiempo la mayoría no lo sean y se limiten a ejecutar rutinas seguras relativamente eficientes de modo que la innovación es importante pero relativamente marginal (unos pocos se arriesgan y crean y la mayoría imita a los exitosos). Las diferencias y la variabilidad son hechos empíricos y cuantitativos y su importancia relativa frente a la igualdad y la constancia sólo puede conocerse observando la realidad y midiendo de alguna manera. Cuando las diferencias son escasas los agregados tienen sentido, y si el cambio es pequeño el equilibrio es una buena aproximación sobre la cual la novedad puede tratarse como un perturbación. Que la realidad de lo humano y social sea cambiante es que puede cambiar, no que tenga que hacerlo.

Los praxeólogos insisten en la acción intencional como acción humana, pero parte importante del comportamiento humano no es intencional sino reactivo y rutinario. La conducta intencional es característica de la especie humana pero no es única a ella (aunque sí su nivel de sofisticación), y su importancia relativa respecto a lo reactivo es una cuestión empírica. No todo es agencia intencional, y la realidad queda distorsionada si sólo se percibe a través de ese filtro explicativo, que es un modo de pensamiento muy importante en la mente humana pero puede abusarse de él. La neurociencia muestra que comportamientos que parecen intencionales incluso al propio agente pueden resultar engañosos. La agencia mental especializada del comportamiento intencional no solo lo produce sino que también lo usa para interpretar, en ocasiones de forma muy imperfecta, la conducta reactiva del individuo. Presentar al ser humano como empresarial, creativo, original, descubridor, puede resultar muy atractivo (y utilizarse para el proselitismo) pero tal vez no sea completamente realista. 